\title{
вмJ Global Health What lessons does the COVID-19 pandemic hold for global alcohol policy?
}

\author{
June Yue Yan Leung, ${ }^{1}$ Shiu Lun Au Yeung (1) , ${ }^{2}$ Tai Hing Lam, ${ }^{2}$ Sally Casswell ${ }^{1}$
}

To cite: Leung JYY, Au Yeung SL, Lam TH, et al. What lessons does the COVID-19 pandemic hold for global alcohol policy?BMJ Global Health 2021;6:e006875. doi:10.1136/ bmjgh-2021-006875

Received 12 July 2021 Accepted 13 July 2021

Check for updates

(c) Author(s) (or their employer(s)) 2021. Re-use permitted under CC BY-NC. No commercial re-use. See rights and permissions. Published by BMJ.

${ }^{1}$ SHORE \& Whariki Research Centre, Massey University, Auckland, New Zealand ${ }^{2}$ School of Public Health, Li Ka Shing Faculty of Medicine, The University of Hong Kong, Hong Kong SAR, China

Correspondence to Dr June Yue Yan Leung; Y.Leung@massey.ac.nz
COVID-19 is a 'syndemic', its impact exacerbated by existing socioeconomic inequalities that also underpin the global burden of noncommunicable diseases (NCDs). ${ }^{1}$ Lockdown measures have changed patterns of alcohol consumption and disrupted the provision of health services for people with NCDs. Moreover, insufficient vaccines and therapeutics, combined with a higher burden of NCDs, mean that some low- and middle-income countries (LMICs) such as Brazil, India and Mexico now suffer from the world's highest COVID-19 death tolls. As described by the WHO director-general, "the world is on the brink of a catastrophic moral failure-and the price of this failure will be paid with lives and livelihoods in the world's poorest countries. ${ }^{2}$ Effective policy responses for both COVID-19 and NCDs are urgently needed, to protect future generations from further health inequities.

The world's focus on COVID-19 has diverted attention from the equally devastating epidemic of NCDs. In May 2021, the Independent Panel for Pandemic Preparedness and Response recommended a Framework Convention to strengthen international governance for pandemics. ${ }^{3}$ For over 15 years, civil society has been calling for a similar international instrument for alcohol control, but WHO's recently proposed action plan (20222030) to strengthen implementation of the global strategy to reduce the harmful use of alcohol $^{4}$ is a far weaker response. WHO has acknowledged the need for stronger global governance mechanisms for alcohol, akin to its Framework Convention on Tobacco Control (FCTC). ${ }^{5}$ An evaluation of WHO's global action plan on NCDs (2013-2020) also showed incremental progress made in policies addressing tobacco use, but none of the other risk factors including alcohol. ${ }^{6}$ However, in 2020, the WHO Executive Board (EB) rejected a proposal by Thailand and
Summary box

- The COVID-19 pandemic has highlighted inequities in the global burden of non-communicable diseases and the relative lack of attention to policy addressing alcohol use.

- While a Framework Convention for pandemics has been suggested, a proposal for a similar instrument for alcohol was rejected in favour of a non-binding global action plan to strengthen implementation of the global strategy to reduce the harmful use of alcohol.

- To reduce health inequities, stronger and independent leadership by WHO is vital, backed by highincome countries acting in solidarity with low- and middle-income countries (LMICs) and civil society, to sustain support for LMICs and counter interference by entities with conflicts of interest.

- To achieve these goals, governments and civil society should continue to advocate for a Framework Convention for alcohol, given alcohol meets the same conditions that formed the basis for WHO's Framework Convention on Tobacco Control.

other LMICs to "convene a working group to review and propose the feasibility of developing an international instrument for alcohol control'. ${ }^{4}$ This proposal was strongly opposed by several high-income countries (HICs) such as the USA, Australia and New Zealand. ${ }^{7-9}$

What can we learn from the COVID-19 pandemic that may be applied to global alcohol policy? First, actions prioritising national interests risk widening health inequities and worsening global burden of disease. 'Vaccine nationalism' among HICs has exacerbated insufficient COVID-19 vaccines for LMICs, prolonging the pandemic for all countries. HICs that oppose a Framework Convention on Alcohol Control (FCAC) are usually exporters of alcohol or headquarters of transnational alcohol corporations, suggesting primacy of commercial interests over health in these countries. Here an FCAC would serve to counter the negative effects of 
commercial interests on alcohol policy. Because of the FCTC, the protection of tobacco control is now considered in international trade negotiations and the World Trade Organization. ${ }^{1011}$ Australia's experience with the Trans-Pacific Partnership negotiations illustrates that alcohol never received attention due to the lack of an international treaty. ${ }^{12}$

Second, the interests of LMICs must be better represented in global health policy development. The concentration of manufacturing capacity of vaccines, diagnostics and therapeutics in HICs has been a major contributor to inequity in the COVID-19 pandemic. ${ }^{3}$ Similarly, LMICs suffer disproportionately from alcohol-attributable burden of disease, ${ }^{13}$ are the targets for market expansion by the transnational producers of alcohol, and yet are under-represented in the negotiation processes for alcohol policy at WHO. At the WHO EB meeting in 2020, while the proposal in favour of an FCAC by Thailand and other LMICs (Bangladesh, Bhutan, Indonesia, Iran, Sri Lanka and Vietnam) failed to gain support early on, HICs (Australia, Canada, European Union, New Zealand, Norway and USA) were the key actors in bilateral consultations during the subsequent negotiations with the chair (Japan), also a HIC. ${ }^{7}$ On the other hand, the formation of alliances between HICs and LMICs was essential to the success of the FCTC negotiations. The FCTC was initially championed by Canada, with the backing of Finland, Mexico and Tanzania. ${ }^{14}$ Brazil then played a leadership role in the FCTC negotiations, expanding the participation of LMICs. ${ }^{15}$ An FCAC will require support from governments of HICs to uphold equity for LMICs.

Third, continued solidarity with civil society is needed in responding to global health threats. Civil society organisations (CSOs) have played a key role in the pandemic response, for example, by providing information to the public, supporting the needs of vulnerable groups, and facilitating accountability over state and private sector decisions. ${ }^{16}$ CSOs fill similar roles in alcohol control, and many international CSOs, such as the Global Alcohol Policy Alliance, Green Crescent, Movendi International, NCD Alliance, Union for International Cancer Control and World Medical Association, have shown strong support for an FCAC. Locally, CSOs must also advocate for their governments' backing of an FCAC. A broad coalition of CSOs would enable mobilisation of political will globally, although importantly, organisations funded by the alcohol industry employ sophisticated strategies to position themselves as 'partners' in addressing alcoholrelated harm, including sponsoring intergovernmental events, educational interventions and alcohol research. ${ }^{17}$ While CSOs should be recognised as important partners, their roles must be clearly distinguished from entities with potential conflicts of interest in alcohol control.

Finally, stronger and independent leadership by WHO is critical. Alcohol control is severely under-resourced at the WHO level, ${ }^{18}$ with member states reporting insufficient technical assistance and lack of coordination as barriers to implementation of effective alcohol policies. ${ }^{19}$
In contrast, tobacco control being the top priority of a former WHO director-general meant that resources could be devoted to the development of an FCTC. ${ }^{14}$ The COVID-19 pandemic has also exposed structural problems with WHO, especially its precarious funding, with the Independent Panel noting that WHO's current financing model 'is a major risk to the integrity and independence of its work. ${ }^{3}$ A shortfall in funding for the global COVID-19 response led to the WHO Foundation's establishment to broaden WHO's donor pool. ${ }^{20}$ Notably, the foundation's gift acceptance policy only lists the tobacco and arms industries as 'strictly off limits', ${ }^{21}$ leaving room for influence from other commercial actors including the alcohol industry. The foundation's COVID-19 Solidarity Response Fund ${ }^{22}$ has received funding from entities with clear conflicts of interest in NCD control, including manufacturers of breast milk substitutes, sugary drinks and ultra-processed foods, raising concerns about industry interference in WHO's development of global health policy. WHO requires much stronger financial support from member states, particularly HICs, to maintain its independence and integrity. Against the backdrop of the United Nations' promotion of public-private partnerships and WHO's continued dialogue with the alcohol industry, a Framework Convention enabling clearer rules of engagement with the industry is now more important than ever.

To reduce global health inequities for LMICs and counter industry interference, WHO must be supported by governments of HICs acting in solidarity with LMICs and civil society. As a Framework Convention for pandemics is being considered, we argue that alcohol requires a similar international response. Like tobacco, alcohol is a group 1 carcinogen, meaning that any use is harmful. Alcohol has also met the same conditions that formed the basis for the FCTC: (1) the scope of the damage makes alcohol a public health tragedy of the first order; (2) the problem exists in every country; (3) key elements, such as cross-border marketing, transcend national boundaries; and (4) the problem has proven incapable of being fully tamed by countries acting in isolation. ${ }^{23}$ Such a legal instrument is vital to minimise the influence of the transnational alcohol industry, which operates in ways very similar to the tobacco industry and has contributed to failure by governments to implement more effective alcohol policies. ${ }^{17}$ While an FCAC has been called politically infeasible ${ }^{24}$ the FCTC was also criticised as 'ambitious to a fault' but eventually made possible by several key factors: member state leadership in coalition building, strong support by civil society and WHO leadership. ${ }^{14}$ We should not lose sight of these lessons.

Twitter Shiu Lun Au Yeung @Ryan_Au_Yeung

Contributors JYYL drafted the article. SLAY, THL and SC critically revised the article and approved of the final version.

Funding This work was supported by the Sir Robert Kotewall Professorship in Public Health, School of Public Health, The University of Hong Kong.

Competing interests None declared. 
Patient consent for publication Not required.

Provenance and peer review Not commissioned; internally peer reviewed.

Data availability statement There are no data in this work.

Open access This is an open access article distributed in accordance with the Creative Commons Attribution Non Commercial (CC BY-NC 4.0) license, which permits others to distribute, remix, adapt, build upon this work non-commercially, and license their derivative works on different terms, provided the original work is properly cited, appropriate credit is given, any changes made indicated, and the use is non-commercial. See: http://creativecommons.org/licenses/by-nc/4.0/.

ORCID iD

Shiu Lun Au Yeung http://orcid.org/0000-0001-6136-1836

\section{REFERENCES}

1 Bambra C, Riordan R, Ford J, et al. The COVID-19 pandemic and health inequalities. J Epidemiol Community Health 2020;74:964.

2 World Health Organization. WHO director-general's opening remarks at 148th session of the Executive Board, 2021. Available: https:// www.who.int/director-general/speeches/detail/who-director-generals-opening-remarks-at-148th-session-of-the-executive-board [Accessed 31 May 2021].

3 The Independent Panel for Pandemic Preparedness \& Response. COVID-19: make it the last pandemic, 2021

4 Casswell S, Rehm J. Reduction in global alcohol-attributable harm unlikely after setback at WHO Executive Board. Lancet 2020;395:1020-1.

5 Commission on Social Determinants of Health. Closing the gap in a generation: health equity through action on the social determinants of health. Geneva: World Health Organization, 2008.

6 World Health Organization. Political declaration of the third highlevel meeting of the General Assembly on the prevention and control of non-communicable diseases. Mid-point evaluation of the implementation of the WHO global action plan for the prevention and control of noncommunicable diseases 2013-2020. Geneva: World Health Organization, 2021. https://apps.who.int/gb/ebwha/pdf_files/ WHA74/A74_10Add1-en.pdf

7 Tangcharoensathien V. Accelerating action to reduce the harmful use of alcohol. Global Alcohol Policy Conference, Dublin, 2020.

8 Movendi International. Who: countries Request accelerated action on alcohol, 2020. Available: https://movendi.ngo/news/2020/02/ 10/who-countries-request-accelerated-action-on-alcohol-harm/ [Accessed $12 \mathrm{Jul} 2021]$

9 Patnaik P. WHO 146th Executive Board Meeting - the technical meets the political, 2020. Available: https://www.internationalhealthp olicies.org/featured-article/who-146th-executive-board-meeting-thetechnical-meets-the-political/ [Accessed 12 July 2021].

10 O'Brien P. Reducing the power of the alcohol industry in trade and investment agreement negotiations through improved global governance of alcohol comment on "what generates attention to health in trade policy-making? Lessons from success in tobacco control and access to medicines: a qualitative study of australia and the (comprehensive and progressive) trans-pacific partnership". Int $J$ Health Policy Manag 2021. doi:10.34172/ijhpm.2021.10. [Epub ahead of print: 17 Feb 2021].

11 Eckhardt J, Holden C, Callard CD. Tobacco control and the world trade organization: mapping member states' positions after the framework convention on tobacco control. Tob Control 2016;25:692-8.

12 Townsend B, Friel S, Schram A, et al. What generates attention to health in trade PolicyMaking? lessons from success in tobacco control and access to medicines: a qualitative study of Australia and the (comprehensive and progressive) Trans-Pacific partnership. Int $J$ Health Policy Manag 2020. doi:10.34172/ijhpm.2020.80. [Epub ahead of print: 07 Jun 2020].

13 Shield K, Manthey J, Rylett M, et al. National, regional, and global burdens of disease from 2000 to 2016 attributable to alcohol use: a comparative risk assessment study. Lancet Public Health 2020;5:e51-61.

14 Roemer R, Taylor A, Lariviere J. Origins of the WHO Framework Convention on Tobacco Control. Am J Public Health 2005;95:936-8.

15 Lee K, Chagas LC, Novotny TE. Brazil and the Framework Convention on Tobacco Control: global health diplomacy as soft power. PLoS Med 2010;7:e1000232.

16 CIVICUS. Solidarity in the time of COVID-19. civil society responses to the pandemic, 2020. Available: https://www.civicus.org/ documents/reports-and-publications/SOCS/2020/solidarity-in-thetime-of-covid-19_en.pdf [Accessed 12 July 2021].

17 Casswell S. Vested interests in addiction research and policy. Why do we not see the corporate interests of the alcohol industry as clearly as we see those of the tobacco industry? Addiction 2013;108:680-5.

18 Braaten ES, Casswell S. Despite COVID-19 Member States need to adequately resource WHO's work to address alcohol harm. Int J Health Policy 2020.

19 Jernigan DH, Trangenstein PJ. What's next for WHO's global strategy to reduce the harmful use of alcohol? Bull World Health Organ 2020;98:222-3.

20 Maani N, Van Schalkwyk MC, Petticrew M, et al. The new WHO Foundation - global health deserves better. BMJ Glob Health 2021;6:e004950.

21 WHO Foundation. WHO Foundation gift acceptance policy Available: https://who.foundation/cms/wp-content/uploads/2021/03/ WHOF_Gift_Acceptance_Policy_17-03-21.pdf [Accessed 13 Jun 2021].

22 WHO Foundation. Supporters of the COVID-19 Solidarity Response Fund for WHO. Available: https://covid19responsefund.org/en/ supporters [Accessed 13 Jun 2021].

23 Joossens L. Improving public health through an International Framework Convention on Tobacco Control. Geneva: World Health Organization, 1999

24 Taylor AL, Dhillon IS. An international legal strategy for alcohol control: not a framework convention--at least not yet. Addiction 2013;108:450-5. 